\title{
Do physician recommendations for colorectal cancer screening differ by patient age?
}

\author{
Maida J Sewitch $\mathrm{PhD}^{1}$, Caroline Fournier $\mathrm{MSc}^{2}$, Martin Dawes $\mathrm{MD}^{3}$, Mark Yaffe MD MClSc${ }^{3}$, Linda Snell MD ${ }^{4}$,
} Mark Roper $\mathrm{MD}^{3}$, Patrizia Zanelli $\mathrm{MDCM}^{5}$, Alan Pavilanis $\mathrm{MD}^{3}$

\begin{abstract}
MJ Sewitch, C Fournier, M Dawes, et al. Do physician recommendations for colorectal cancer screening differ by patient age? Can J Gastroenterol 2007;21(7):435-438.

Colorectal cancer screening is underutilized, resulting in preventable morbidity and mortality. In the present study, age-related and other disparities associated with physicians' delivery of colorectal cancer screening recommendations were examined. The present crosssectional study included 43 physicians and 618 of their patients, aged 50 to 80 years, without past or present colorectal cancer. Of the 285 screen-eligible patients, $45 \%$ received a recommendation. Multivariate analyses revealed that, compared with younger nondepressed patients, older depressed patients were less likely to receive fecal occult blood test recommendations, compared with no recommendation $(\mathrm{OR}=0.31,95 \% \mathrm{CI} 0.09$ to 1.02$)$, as well as less likely to receive colonoscopy recommendations, compared with no recommendation $(\mathrm{OR}=0.14 ; 95 \% \mathrm{CI} 0.03$ to 0.66$)$. Comorbidity and marital status were associated with delivery of fecal occult blood test and colonoscopy recommendations, respectively, compared with no recommendation. In summary, patient age and other characteristics appeared to influence physicians' delivery of colorectal cancer screening and choice of modality.
\end{abstract}

Key Words: Ageism; Colorectal cancer; Disparity; Screening

\section{Les recommandations des médecins à l'égard du dépistage du cancer colorectal diffèrent- elles selon l'âge des patients?}

\begin{abstract}
Le dépistage du cancer colorectal est sous-utilisé, ce qui entraîne une morbidité et une mortalité qui pourraient être prévenus. Dans la présente étude, on évalue les disparités reliées à l'âge et à d'autres facteurs associés aux recommandations du médecin en matière de dépistage du cancer colorectal. La présente étude transversale incluait 43 médecins et 618 de leurs patients, de 50 à 80 ans, qui n'avaient jamais été atteint de cancer colorectal. Des 285 patients admissibles au dépistage, $45 \%$ ont reçu une recommandation. D'après les analyses multivariées, comparativement aux patients non dépressifs plus jeunes, les patients dépressifs plus âgés étaient moins susceptibles de se faire recommander de subir un test de recherche de sang occulte dans les selles que de ne recevoir aucune recommandation $(\mathrm{RC}=0,31,95 \% \mathrm{IC}=0,09$ à 1,02$)$ et également moins susceptibles de se faire recommander de subir une coloscopie que de ne recevoir aucune recommandation $(\mathrm{RC}=0,14,95 \% \mathrm{IC}=0,03$ à 0,66). La comorbidité et l'état matrimonial s'associaient aux recommandations de test de recherche de sang occulte dans les selles et de coloscopie, respectivement, par rapport à l'absence de recommandation. Bref, l'âge du patient et d'autres caractéristiques semblent influer sur la prestation, par le médecin, du dépistage du cancer colorectal et sur le choix de modalités.
\end{abstract}

C olorectal cancer (CRC) screening is underutilized despite the evidence supporting reductions in CRC morbidity and mortality in average-risk individuals who are 50 years of age and older (1-4). Underutilization in CRC screening may stem, in part, from the lack of consensus regarding screening guidelines across organizations (5-7). However, patient demographic and clinical characteristics may also account for physicians' decisions to recommend screening (8-11). Although most reports focused on racial, ethnic and socioeconomic status as sources of screening disparities (12-17), ageism has been suggested as a potential barrier to delivery of screening (11). Ageism, for the purposes of the present study, is defined as discrimination against elderly people. Because physicians may disfavour the elderly when delivering preventive health care services, the present report addresses the influence of patient's age on physician's delivery of a recommendation for CRC screening in primary care. Given that individuals 50 years of age and older constitute a rapidly growing population and that increasing age is associated with increasing cancer rates, the sources of age-related disparities in delivery of CRC screening warrant further elucidation.

\section{METHODS}

\section{Participants and data sources}

A cross-sectional study was conducted among family and internal medicine physicians and their patients at three McGill Universityaffiliated centres in Montreal, Quebec (2004 to 2005). Delivery of CRC screening recommendations included fecal occult blood test (FOBT), colonoscopy, double-contrast barium enema (DCBE) and flexible sigmoidoscopy (FS). Physician's delivery of CRC screening recommendation was assessed by physician self-administered questionnaire immediately following the patient's index office visit, defined as a scheduled appointment for any of the following: annual examination, periodic health examination, follow-up or specific problem. Eligible patients were aged 50 to 80 years, under treatment at the clinic for at least two years, and without past or

${ }^{1}$ Department of Medicine, McGill University; ${ }^{2}$ Department of Clinical Epidemiology, The Research Institute of the McGill University Health Centre; ${ }^{3}$ Department of Family Medicine; ${ }^{4}$ Division of General Internal Medicine and Centre for Medical Education; ${ }^{5}$ Divisions of General Internal Medicine and Critical Care, McGill University, Montreal, Quebec

Correspondence: Dr Maida J Sewitch, McGill University Health Centre, 687 Pine Avenue West, V Building, Montreal, Quebec H3A 1A1.

E-mail maida.sewitch@mcgill.ca

Received for publication June 21, 2006. Accepted October 3, 2006 


\begin{tabular}{|c|c|c|c|}
\hline Characteristic & $\begin{array}{c}\text { Age }<65 \text { years } \\
(n=149) \\
n(\%)\end{array}$ & $\begin{array}{c}\text { Age } \geq 65 \text { years } \\
(n=136) \\
n(\%)\end{array}$ & $\mathbf{P}$ \\
\hline Sex & & & 0.379 \\
\hline Male & $59(39.6)$ & $47(34.6)$ & \\
\hline Female & $90(60.4)$ & $89(65.4)$ & \\
\hline Marital status & & & 0.065 \\
\hline Single/divorced/widowed & $53(35.6)$ & $63(46.3)$ & \\
\hline Married & $96(64.4)$ & $73(53.7)$ & \\
\hline Education & & & 0.134 \\
\hline High school or less & $49(32.9)$ & $56(41.5)$ & \\
\hline College or university & $100(67.1)$ & $79(58.5)$ & \\
\hline Comorbidity & & & $<0.0001$ \\
\hline None & $107(71.8)$ & $67(49.3)$ & \\
\hline At least one & $42(28.2)$ & $69(50.7)$ & \\
\hline Depression & & & 0.014 \\
\hline Absent & $89(60.5)$ & $99(74.4)$ & \\
\hline Present & $58(39.5)$ & $34(25.6)$ & \\
\hline \multicolumn{4}{|l|}{ Screening recommendation } \\
\hline Any modality & $78(52.7)$ & $50(36.8)$ & 0.0056 \\
\hline FOBT & $33(22.3)$ & $25(17.8)$ & 0.343 \\
\hline Colonoscopy & $44(29.7)$ & 26 (18.5) & 0.028 \\
\hline
\end{tabular}

FOBT Fecal occult blood test

present CRC. Patient characteristics were assessed by self-administered questionnaire at the index visit and included sociodemographic characteristics, cancer screening history and eligibility, comorbidity (Charlson co-morbidity index) (18) and depression (Center for Epidemiologic Studies Depression Scale) (19,20). Screeneligibility was defined as not having received any of the following: FOBT in the past two years, colonoscopy in the past 10 years and DCBE or FS in the past five years.

\section{Statistical analyses}

Patients were stratified by age ( 50 to 64 years and 65 to 80 years). Characteristics were compared using $\chi^{2}$ and $t$ tests, as appropriate. Because only one recommendation was given for DCBE and FS each, these patients were excluded from further analysis. Multinomial logistic regression analyses were performed to assess patient characteristics as predictors of a three-category outcome: not delivering a screening recommendation, delivering an FOBT recommendation and delivering a colonoscopy recommendation. The SAS CATMOD (SAS Inc, USA) procedure (21) was used to contrast the three mutually exclusive categories for each of the following outcome scenarios of recommendation delivered: FOBT versus none, colonoscopy versus none and FOBT versus colonoscopy. ORs and 95\% CIs were generated for each outcome scenario. Independent variables included patient age, depression, comorbidity, marital status and an age group by depression status interaction. Comorbidity was dichotomized at the cutpoint of one comorbid condition (median=0.67). Sex was excluded from the final model because it was not statistically significant and did not confound the age-delivery of recommendation relationship. To account for limited statistical power of testing the interaction, given unequal numbers of patients in the two groups, the decision was taken to include the interaction if it was significant at a liberal 0.10 level. For all other tests, statistical significance was set at $\mathrm{P}=0.05$.

\section{RESULTS}

In total, 43 physicians and 618 patients participated. Of the $285(46 \%)$ screen-eligible patients, 48\% were aged 65 years and older. Compared with screen-eligible patients, nonscreeneligible patients were significantly older (67 versus 65 years; $\mathrm{P}=0.003)$ and had more comorbidity $(48 \%$ versus $38 \%$; $\mathrm{P}=0.02$ ) (data not shown). Table 1 compares the characteristics and screening recommendations of screen-eligible patients by age group. Compared with younger patients, older patients had significantly more comorbidity and less depression. A significantly smaller proportion of older patients was recommended screening compared with their younger counterparts ( $37 \%$ versus $53 \%, \mathrm{P}=0.0056$ ). FOBT recommendation did not differ by age group. Colonoscopy recommendation was given to more younger than older patients (30\% versus $19 \%$, $\mathrm{P}=0.028)$.

Table 2 shows the associations between patient characteristics and the three outcome scenarios. In univariate analyses for FOBT recommendation (column 2), patients with comorbidity $(\mathrm{OR}=0.52,95 \% \mathrm{CI} 0.27$ to 0.99$)$ were less likely to receive an FOBT recommendation compared with no recommendation. A trend was revealed that indicated older patients $(\mathrm{OR}=0.59$, 95\% CI 0.32 to 1.09 ) were less likely to receive an FOBT recommendation compared with no recommendation. In multivariate analysis, the age group by depression interaction was found to be statistically significant. This interaction indicated that older depressed patients $(\mathrm{OR}=0.31,95 \% \mathrm{CI} 0.09$ to 1.02$)$ versus younger nondepressed patients were less likely to receive an FOBT recommendation, compared with no recommendation. In addition, a trend was revealed showing that patients with comorbidity $(\mathrm{OR}=0.57,95 \% \mathrm{CI} 0.29$ to 1.13 ) were less likely to receive an FOBT recommendation compared with no recommendation.

In univariate analyses for colonoscopy recommendation (column 3), older patients $(\mathrm{OR}=0.48,95 \% \mathrm{CI} 0.27$ to 0.86$)$ were less likely to receive a colonoscopy recommendation while married patients ( $\mathrm{OR}=2.05,95 \% \mathrm{CI} 1.13$ to 3.74 ) were more likely to receive a colonoscopy recommendation, compared with no recommendation. In multivariate analyses, married patients $(\mathrm{OR}=1.86,95 \% \mathrm{CI} 0.99$ to 3.51$)$ were more likely to receive a colonoscopy recommendation compared with no recommendation, although this association did not reach statistical significance. In addition, the age by depression interaction was found to be statistically significant. This interaction implied that older depressed patients $(\mathrm{OR}=0.14$, $95 \%$ CI 0.03 to 0.66 ) were less likely to receive a colonoscopy recommendation than younger nondepressed patients, compared with no recommendation.

In both univariate and multivariate analyses that compared FOBT and colonoscopy recommendations, no associations were found between patient characteristics and physician delivery of screening recommendations.

\section{DISCUSSION}

Most current guidelines advocate that persons over the age of 50 years be screened with FOBT every one to two years or with colonoscopy every 10 years (5-7). Although disparities in CRC screening recommendation have been documented, their nature and role were unclear. Our study provides evidence for 
TABLE 2

Univariate and multivariate results of multinomial logistic regression analyses: Associations between patient characteristics and physician recommendations for colorectal cancer screening $(n=283)$

\begin{tabular}{|c|c|c|c|}
\hline Characteristic & $\begin{array}{c}\text { FOBT versus none } \\
\text { OR }(95 \% \mathrm{Cl}) \\
\text { AOR }(95 \% \mathrm{Cl})\end{array}$ & $\begin{array}{c}\text { Colonoscopy versus none } \\
\text { OR }(95 \% \mathrm{Cl}) \\
\text { AOR }(95 \% \mathrm{Cl})\end{array}$ & $\begin{array}{c}\text { FOBT versus colonoscopy } \\
\text { OR }(95 \% \mathrm{Cl}) \\
\text { AOR }(95 \% \mathrm{Cl})\end{array}$ \\
\hline \multicolumn{4}{|l|}{ Age group } \\
\hline \multirow[t]{2}{*}{$\geq 65$ years } & $0.59(0.32-1.09)^{*}$ & $0.48(0.27-0.86)^{\star * *}$ & $1.23(0.60-2.52)$ \\
\hline & $0.77(0.37-1.63)$ & $0.78(0.38-1.60)$ & $0.99(0.42-2.32)$ \\
\hline \multirow[t]{2}{*}{ Present } & $0.64(0.32-1.25)$ & $0.71(0.39-1.32)$ & $0.89(0.41-1.96)$ \\
\hline & $0.74(0.30-1.78)$ & $1.15(0.52-2.55)$ & $0.64(0.24-1.66)$ \\
\hline \multicolumn{4}{|c|}{ Age by depression interactions ${ }^{\dagger}$} \\
\hline$<65$ years by absent & 1.0 & 1.0 & 1.0 \\
\hline$\geq 65$ years by present & $0.31(0.09-1.02)^{\star *}$ & $0.14(0.03-0.66)^{\star \star \star}$ & $2.18(0.36-13.26)$ \\
\hline Married & $1.29(0.68-2.46)$ & $1.86(0.99-3.51)^{\star *}$ & $0.69(0.32-1.49)$ \\
\hline \multicolumn{4}{|l|}{ Comorbidity } \\
\hline None & 1.0 & 1.0 & 1.0 \\
\hline \multirow[t]{2}{*}{ At least one } & $0.52(0.27-0.99)^{\star \star \star}$ & $0.64(0.36-1.15)$ & $0.82(0.38-1.73)$ \\
\hline & $0.57(0.29-1.13)^{\star}$ & $0.77(0.41-1.44)$ & $0.75(0.34-1.64)$ \\
\hline
\end{tabular}

Multinomial logistic models assessing one of the following outcome scenarios: delivery of fecal occult blood test (FOBT) or no recommendation (column 2); delivery of colonoscopy or no recommendation (column 3); delivery of FOBT or colonoscopy (column 4); ${ }^{*} P \leq 0.10$; ${ }^{* \star} P=0.05$; ${ }^{* * *} P<0.01$; ${ }^{+}$Univariate results not available for the age group by depression interaction. AOR Adjusted odds ratio

age-related disparities in physician delivery of CRC screening recommendation to screen-eligible, average-risk persons. The interaction between age group and depression was the most important determinant of physicians' delivery of a colonoscopy recommendation. Although a greater proportion of patients in the younger age group were depressed, only depression in the older age group was associated with lack of delivery of a recommendation for colonoscopy. Several reasons for this observation can be postulated. Primary care patients who present with chronic depression may offset physicians' screening offerings to address the more pressing issue of depression. Because depression in younger patients did not seem to influence delivery of CRC screening recommendation, older age may be a key factor driving physicians' decision to not recommend colonoscopy screening. Physicians may be taking into account the arduous preparation and invasiveness of the procedure, which may be more difficult at advanced ages. Alternatively, primary care patients who present with a new, unexplained episode of depression may prompt physicians to recommend screening because a new depressive episode may be an underlying symptom of occult malignancies such as CRC $(22,23)$. The age by depression interaction also indicated that physicians recommended FOBT 69\% less often to older depressed patients versus younger nondepressed patients. Similarly, because FOBT is self-administered, providers may perceive that older depressed patients will find preparation and performance of the examination to be a daunting task and will, therefore, be less compliant.

The role of comorbidity was explored as a factor that might influence physician delivery of screening recommendations. We expected that, because comorbidity generally increases with increasing age, older patients would have more comorbidity and would be less likely to receive a screening recommendation regardless of the modality. However, there was no association between an age by comorbidity interaction and delivery of screening recommendation for any modality. In contrast, patients with comorbidity, regardless of age, were marginally less likely to receive an FOBT recommendation. The clinical importance of this finding lies in the fact that physicians often consider quality versus quantity of life when offering screening for a malignancy (24) and may perceive that patients with comorbidity would not derive sufficient benefit from screening. Furthermore, providers may not offer FOBT to patients with comorbid conditions because FOBT may be more difficult to complete than examinations that are administered by health care professionals. Collectively, these results suggest that comorbidity operates independently of ageism as a determinant of physician delivery of FOBT recommendation.

Additionally, we observed an association between marital status and physician delivery of colonoscopy recommendation. Although this association remained marginally significant in the presence of other patient characteristics, the clinical implication is noteworthy. Physicians may perceive that married compared with unmarried patients have greater social support, are more stable, and may, therefore, be more compliant with screening. This finding suggests that marital status may be an important factor that influences CRC screening recommendations. Another explanation is that marital status may promote screen-seeking behaviour; married patients may ask their physicians to recommend screening because their spouse underwent screening.

Surprisingly, no significant association was found between patient characteristics and delivery of FOBT versus colonoscopy recommendation. Possibly, the lack of identifiable predictors between these two modalities stems from the fact that CRC 
screening guidelines are inconsistent across organizations, leaving physicians to base their modality choice on personal belief and preference. Physicians may adhere to one screening modality and thus may choose to not give any screening recommendation as opposed to recommending an alternative screening modality. Therefore, factors such as patient characteristics that could potentially influence recommendations would not be observed between different screening modalities.

There are several potential study limitations worth discussing. The first is the lack of documentation regarding the nature of the index visit. Primary care physicians are more likely to discuss CRC screening during visits for routine physicals than for follow-ups (25), which may be more common among older individuals with comorbidity. To address this possibility, we assessed the age-comorbidity relationship between screeneligible and nonscreen-eligible patients. We found that older patients had significantly more comorbidity than younger ones in the screen-eligible patients only. Therefore, it is plausible that more of the older, unwell patients were visiting the clinics for follow-ups. However, the lack of association between the age-comorbidity interaction and delivery of a screening recommendation indicates that older patients with comorbidity were as likely to receive a screening recommendation as any other patient. This suggests that, in our study population, the nature of the medical visit did not influence delivery of the screening recommendation. Nevertheless, physicians may have recommended screening regardless of the nature of the medical visit

\section{REFERENCES}

1. Levenson D. CDC says colorectal cancer screening rates remain low. Rep Med Guidel Outcomes Res 2003;14:10,12.

2. McGlynn EA, Asch SM, Adams J, et al. The quality of health care delivered to adults in the United States. N Engl J Med 2003;348:2635-45.

3. Ioannou GN, Chapko MK, Dominitz JA. Predictors of colorectal cancer screening participation in the United States. Am J Gastroenterol 2003;98:2082-91.

4. Nadel MR, Blackman DK, Shapiro JA, Seeff LC. Are people being screened for colorectal cancer as recommended? Results from the National Health Interview Survey. Prev Med 2002;35:199-206.

5. Canadian Task Force on Preventive Health Care. Colorectal cancer screening: Recommendation statement from the Canadian Task Force on Preventive Health Care. CMAJ 2001;165:206-8.

6. Health Canada. Reducing Canadian colorectal cancer mortality through screening, 2002. <www.phac-aspc.gc.ca/publicat/ncccscndcc/ccsrec_e.html> (Version current at June 6, 2007).

7. Canadian Cancer Society. Screening for colorectal cancer, 2004. <www.cancer.ca/ccs/internet/standard/0,3182,3649_10175_7454948 0 langId-en,00.html > (Version current at June 27, 2007).

8. Heflin MT, Oddone EZ, Pieper CF, Burchett BM, Cohen HJ. The effect of comorbid illness on receipt of cancer screening by older people. J Am Geriatr Soc 2002;50:1651-8.

9. Capurso S, Gambassi G, Bernabei R. Cancer in the elderly: To screen or not to screen? J Am Geriatr Soc 2003;51:1816.

10. Freidel D. Colon cancer screening. J Am Geriatr Soc 2001;49:97-8.

11. Jerant AF, Franks P, Jackson JE, Doescher MP. Age-related disparities in cancer screening: Analysis of 2001 Behavioral Risk Factor Surveillance System Data. Ann Fam Med 2004;2:481-7.

12. Gornick ME, Eggers PW, Riley GF. Associations of race, education, and patterns of preventive service use with stage of cancer at time of diagnosis. Health Serv Res 2004;39:1403-27.

13. Cooper GS, Koroukian SM. Racial disparities in the use of and indications for colorectal procedures in Medicare beneficiaries. Cancer 2004;100:418-24.

14. Goel MS, Wee CC, McCarthy EP, Davis RB, Ngo-Metzger Q, Phillips RS. Racial and ethnic disparities in cancer screening: owing to a Hawthorn effect. Another limitation is that because ascertainment of patient screen-eligibility was by selfreport, patients may have misunderstood the test description and failed to report a personal history of screening. Finally, differences between patient's and physician's modality of choice were not documented; physicians may have under-reported screening delivery if the patient immediately refused to comply with the screening modality recommended.

\section{CONCLUSIONS}

Our findings emphasize the complexity of CRC screening disparities that appear to vary with different screening modalities. Our results suggest that patient characteristics such as age and marital status influence delivery of colonoscopy while comorbidity influences delivery of FOBT screening. Age disparities were found for individuals aged 65 years and older who were depressed, which may, in turn, delay delivery of preventive care to older people who would be good candidates for CRC screening and could benefit from early detection and treatment. Further insight into the causes of age-related and other disparities may help overcome barriers to delivery of CRC screening.

ACKNOWLEDGEMENTS: This research was supported by a grant from the Fonds de la Recherche en Santé du Québec (FRSQ). Maida J Sewitch, PhD is supported as a Research Scientist of the Canadian Cancer Society through an award from the National Cancer Institute of Canada.

The importance of foreign birth as a barrier to care. J Gen Intern Med 2003;18:1028-35.

15. O'Malley AS, Forrest CB, Feng S, Mandelblatt J. Disparities despite coverage. Gaps in colorectal cancer screening among Medicare beneficiaries. Arch Intern Med 2005;165:2129-35.

16. Whynes DK, Frew EJ, Manghan CM, Scholefield JH, Hardcastle JD. Colorectal cancer, screening and survival: The influence of socioeconomic deprivation. Public Health 2003;117:389-95.

17. Thompson B, Coronado GD, Solomon CC, McClerran DF, Neuhouser ML, Feng Z. Cancer prevention behaviours and socioeconomic status among Hispanics and non-Hispanic whites in a rural population in the United States. Cancer Causes Control 2002;13:719-28.

18. Katz JN, Chang LC, Sangha O, Fossel AH, Bates DW. Can comorbidity be measured by questionnaire rather than medical record review? Med Care 1996;34:73-84.

19. Radloff LS. The CES-D scale: A self-report depression scale for research in the general population. J Appl Psychol Meas 1977;7:189-98

20. Devins GM, Orme CM, Costello CG, et al. Measuring depressive symptoms in illness populations: Psychometric properties of the Center for Epidemiologic Studies Depression (CES-D) Scale. Psychol Health 1988;2:139-56.

21. Allison PD. Multinomial logit analysis. In: Logistic Regression Using the SAS System: Theory and Application. Cary: John Wiley $\&$ Sons, 2001:111-32.

22. Kroenke CH, Bennett GG, Fuchs C, et al. Depressive symptoms and prospective incidence of colorectal cancer in women. Am J Epidemiol 2005;162:839-48.

23. Croyle RT. Depression as a risk factor for cancer: Renewing a debate on the psychobiology of disease. J Natl Cancer Inst 1998;90:1856-7.

24. Walter LC, Covinsky KE. Cancer screening in elderly patients: A framework for individualized decision making. JAMA 2001;285:2750-6.

25. Patel P, Forjuoh SN, Avots-Avotins A, Patel T. Identifying opportunities for improved colorectal cancer screening in primary care. Prev Med 2004;39:239-46. 


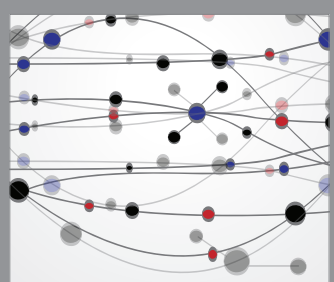

The Scientific World Journal
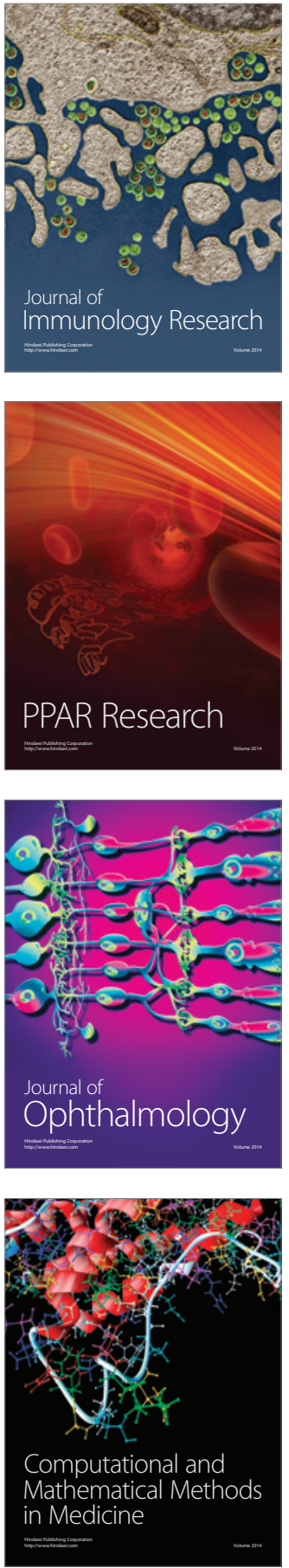

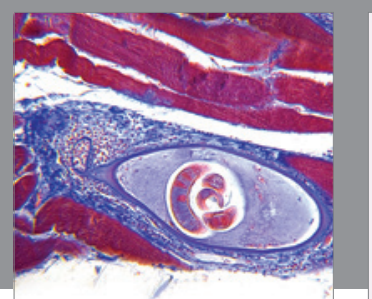

Gastroenterology Research and Practice

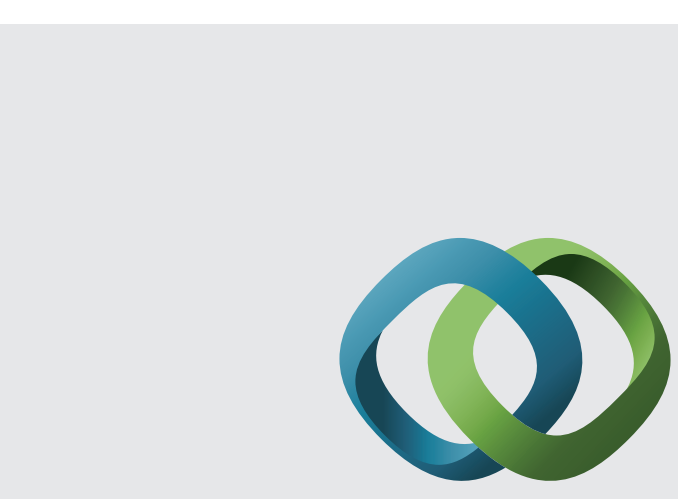

\section{Hindawi}

Submit your manuscripts at

http://www.hindawi.com
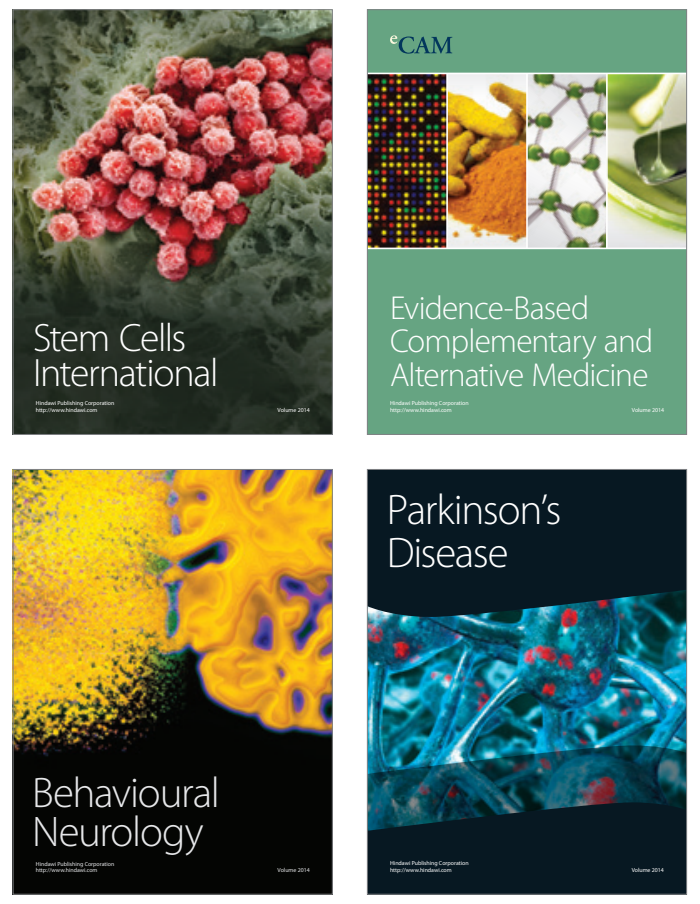
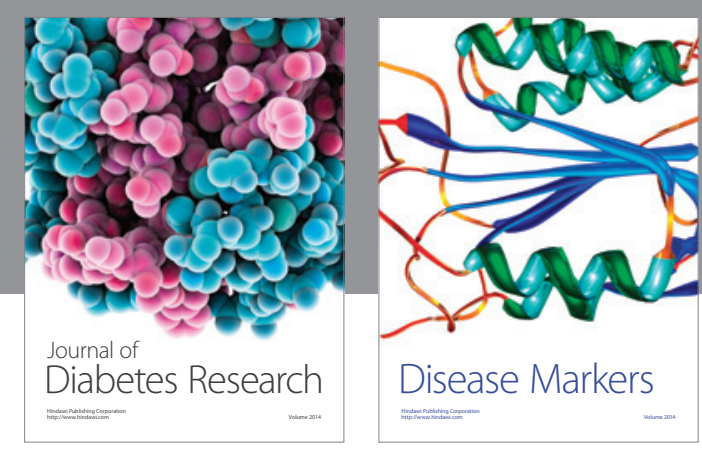

Disease Markers
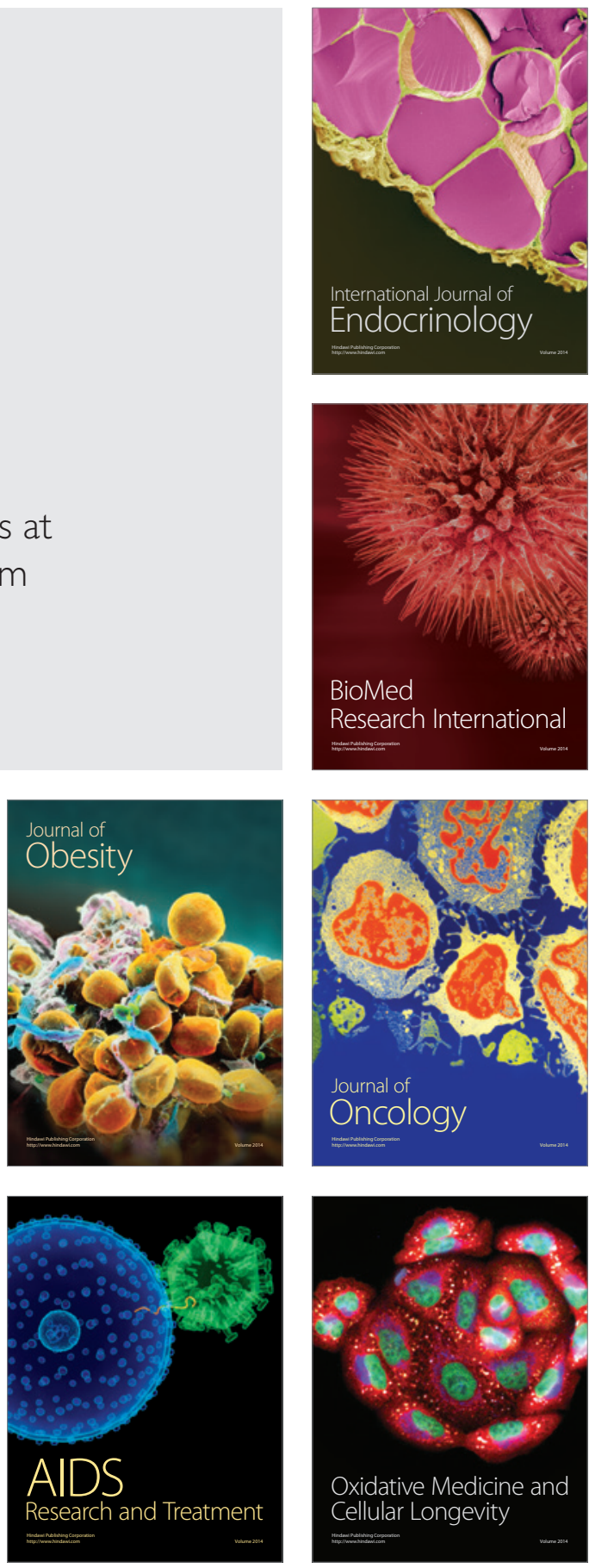